\section{Acknowledgements}

I would like to thank Mr Michael Collins and Dr Steffan Davies for their permission to use the Security Needs Assessment Profile for this research, Dr Christine Kennedy for her advice and support at all stages, Mr Hugo Kelly, and the responsible medical officers who took part.

\section{About the author}

Rowan James McClean is Specialty Registrar ST6 at Knockbracken Healthcare Park in Belfast, UK.

\section{References}

1 Department of Health and Social Security. Revised Report of the Working Party on Security in NHS Psychiatric Hospitals (Glancy Report). HMSO, 1974

2 Home Office, Department of Health and Social Security. Report of the Committee on Mentally Abnormal Offenders, CMND 6244 (Butler Report). HMSO, 1975
3 Beer MD. Psychiatric intensive care and low secure units: where are we now? Psychiatr Bull 2008; 32: 441-3.

4 Kennedy HG. Therapeutic uses of security: mapping forensic menta health services by stratifying risk. Adv Psychiatr Treat 2002; 8: 433-43.

5 Shaw J, Davies J, Morey $\mathrm{H}$. An assessment of the security, dependency $\&$ treatment needs of all patients in secure services in a UK health region. J Forens Psychiatry Psychol 2001; 3: 610-37.

6 Turner T, Salter M. Forensic psychiatry and general psychiatry: reexamining the relationship. Psychiatr Bull 2008; 32: 2-6.

7 Pereira SM, Sarsam M, Bhui K, Paton C. The London Survey of Psychiatric Intensive Care Units: service provision and operational characteristics of National Health Service units. J Psychiatr Intensive Care 2005; 1 : 7-15

8 Collins M, Davies S. The Security Needs Assessment Profile: a multidimensional approach to measuring security needs. Int J Forens Ment Health 2005; 4: 39-52.

9 Reed J. The need for longer term psychiatric care in medium or low security. Crim Behav Ment Health 1997; 7: 201-12.

\title{
Irish Mental Health Act 2001: impact on involuntary admissions in a community mental health service in Dublin
}

\author{
Izu Nwachukwu, ${ }^{1}$ Niall Crumlish, ${ }^{2,3}$ Elizabeth A. Heron, ${ }^{3}$ Michael Gill ${ }^{3}$
}

The Psychiatrist (2010), 34, 436-440, doi: 10.1192/pb.bp.109.028043

${ }^{1}$ St Vincent's University Hospital, Dublin; ${ }^{2}$ St Davnet's Hospital, Monaghan; ${ }^{3}$ St James's Hospital, Dublin, Ireland

Correspondence to Izu Nwachukwu (izunwachukwu@hotmail.com)

\begin{abstract}
Aims and method On 1 November 2006, Ireland's Mental Health Act 2001 was implemented, replacing the country's Mental Treatment Act 1945. We aimed to assess the impact of this change in legislation on the number and duration of involuntary admissions. We undertook a retrospective review of all admissions to a psychiatric admissions unit from January to October 2006 (pre-implementation) and January to October 2007 (post-implementation).
\end{abstract}

Results There were 46 involuntary admissions in the 10-month period under study in 2006, or 33.8 per 100000 population. There were 53 in 2007, or 39.3 per 100000 population. This increase was not significant $(z=-0.7, P=0.46)$, however involuntary admissions formed a larger proportion of all admissions under the Mental Health Act 2001 than under the Mental Treatment Act $1945\left(\chi^{2}=4.2, P=0.04\right)$. There was no difference in the duration of involuntary admissions but under the 2001 Act, involuntary patients had longer periods of voluntary status as part of their admissions than under the 1945 Act.

Clinical implications The introduction of more rigorous procedures for involuntary admission did not significantly change the rate or duration of involuntary admissions in our centre. The finding that involuntary admissions included longer periods of voluntary status suggests that more care is being taken to revoke involuntary admission orders under the Mental Health Act 2001 than under the Mental Treatment Act 1945.

Declaration of interest None.
On 1 November 2006, the Mental Health Act 2001 was implemented in Ireland, replacing the Mental Treatment Act of 1945. Among other provisions, the 2001 Act introduced stricter procedures governing involuntary admissions to designated 'approved centres' for treatment of mental disorders, driven by a recognition that the 1945 Act breached the civil rights of involuntary patients. ${ }^{1,2}$ Most notably, the 1945 Act made no provision for automatic 
review of detention for up to 6 months after a reception order was signed, and anyone declared to be 'a person of unsound mind' could actually be detained indefinitely without any legal requirement that their status be reviewed. ${ }^{3}$

As of November 2006, the new Mental Health Act added three safeguards in that all involuntary patients were entitled to automatic legal representation, an independent psychiatric assessment and a review of their admission by a mental health tribunal within 21 days of detention. Mental health tribunals, which are composed of a barrister/ solicitor, an independent consultant psychiatrist and a lay member, have the authority either to affirm an admission order or to revoke it. ${ }^{4}$

Although the replacement of the 1945 Act was welcomed, ${ }^{2}$ it was not clear what effect implementation of the new Act would have on the frequency and duration of involuntary admissions. An analogous situation occurred in Scotland in 2005, when the Mental Health (Care and Treatment) (Scotland) Act 2003 was implemented. This Act introduced changes to involuntary admission procedures that paralleled those introduced in Ireland a year later, although they were less sweeping, as the act that was replaced in Scotland dated from 1984 rather than 1945. A study of the impact of the Mental Health (Care and Treatment) (Scotland) Act 2003 on admissions to an adult psychiatric unit found that there were fewer involuntary admissions after its implementation, but admissions were longer. ${ }^{5}$ We set out to assess the impact of the introduction of the Mental Health Act 2001 on admissions into the psychiatric unit in the Jonathan Swift Clinic in St James's Hospital, a designated approved centre in south inner-city Dublin. Our hypotheses were: that there would be fewer involuntary admissions under the new 2001 Act than under the 1945 Act; and that involuntary admissions would be shorter under the 2001 Act than under the 1945 Act.

\section{Method}

\section{Setting}

The study took place in the Jonathan Swift Clinic in St James's Hospital, a 51-bed general adult and old age psychiatry unit serving the Dublin South City catchment, which had a total population of 136000 in $2006^{6}$ and 135000 in $2007 .^{7}$ The clinic is a designated approved centre for treatment of mental disorders under the Mental Health Act. $^{7}$ All admissions to the unit from January to October 2006 and January to October 2007 were included. We allowed 2 months following the introduction of the new Act as a period of adjustment. The same months were chosen in each year to control for potential seasonal variations in admissions. We obtained ethical approval for this study from the Internal Audit and Research Department of St James' Hospital.

\section{Data collection and analysis}

A retrospective case-note review was undertaken. We used a pro forma adapted from that used by Smith \& White. ${ }^{5}$ The legal status on admission and discharge was noted and the person's length of stay as an in-patient was calculated, both for periods under the Act and for periods during the same admission for which voluntary status applied. The proportion of each involuntary admission spent detained was calculated by dividing the duration of detention by the overall duration of admission. We used a $t$-test to determine if this proportion varied from year to year, but we transformed the proportions using arcsine/square root transformation, as $t$-tests are not appropriate for simple proportions. To determine whether there was a difference between the rates of involuntary admission year on year, we used a $z$-test, with $95 \%$ confidence intervals for the difference in rates. Otherwise, we used $t$-tests and $\chi^{2}$-tests, with continuity correction as appropriate, to detect differences between groups.

\section{Results}

\section{Characteristics of all admissions}

There were 770 admissions during the study period. In total, 671 admissions (87.1\%) were voluntary and 99 (12.9\%) were involuntary. The characteristics of all admissions are in Table 1, and of involuntary admissions in Table 2. For involuntary patients, the mean duration of detention was 45.4 days (s.d. $=41.6$, median $=32.0$, range $1-168$ ) and the mean duration of all admissions that included an involuntary period was 52.1 days (s.d. $=46.7$, median $=38.0$, range 1-181). The discrepancy between duration of detention and duration of admission (mean $=6.8$ days, s.d. $=15.4$ ) is accounted for by periods that each involuntary patient spent as a voluntary patient, either before involuntary status was commenced or after involuntary status was revoked.

\section{Rate of involuntary admission per 100000 population}

In 2006 the total catchment area population was 136000 and the number of involuntary admissions for the 10-month study period was 46, so that the rate of involuntary admissions was 33.8 per 100000 population. In 2007, the rate was 39.3 per 100000 population, as there were 53 admissions in a catchment population of 135000 . This was an increase of $16.3 \%$. We found a $z$ value of -0.74 and a corresponding $P$ value of 0.46 (95\% CI for the difference in the rates: -19.83 to 8.96 ). This indicated that the difference in rates of involuntary admission year on year was not significant. So as to facilitate comparison with other studies, we multiplied the 10-month rate in each year by 1.2 , to approximate the rate per 100000 population per year. The estimated rate for 2006 was 40.6 per 100000 population per year and the estimated rate for 2007 was 47.1 per 100000 population per year.

\section{Involuntary admissions as proportion of all admissions, by year}

In 2006, the total number of admissions was 432 , and 46 (10.6\%) were involuntary. In 2007, there were 338 admissions, and 53 (15.7\%) were involuntary. Involuntary admissions formed a higher proportion of all admissions in 2007 than in $2006,\left(\chi^{2}=3.8, P<0.05\right)$. Of 46 involuntary admissions in 2006, 6 (13.0\%) were readmissions of people 
Table 1 Characteristics of all admissions in 2006 (Mental Treatment Act 1945) and 2007 (Mental Health Act 2001)

\begin{tabular}{lcc} 
Variable & $\begin{array}{c}\text { Mental Treatment Act } 1945 \\
(n=432)\end{array}$ & $\begin{array}{c}\text { Mental Health Act } 2001 \\
(n=338)\end{array}$ \\
\hline Male, $n(\%)$ & $228(52.8)$ & $31.7(49.8)$ \\
\hline Duration of admission, days: mean (s.d.) & $430.3)$ \\
\hline Age on admission, years: mean (s.d.) & $43.9(16.6)$ \\
\hline Involuntary status during admission, $n(\%)^{a}$ & $46(10.6)$ & $28.1(52.0)$ \\
\hline
\end{tabular}

a. Difference significant at $P<0.05$.

Table 2 Characteristics of involuntary admissions in 2006 (Mental Treatment Act 1945) and 2007 (Mental Health Act 2001)
\begin{tabular}{lcc} 
Variable & $\begin{array}{c}\text { Mental Treatment Act 1945 } \\
(n=46)\end{array}$ & $\begin{array}{c}\text { Mental Health Act } 2001 \\
(n=53)\end{array}$ \\
\hline Male, $n(\%)$ & $31(67.4)$ & $29(54.7)$ \\
\hline Age on admission, years: mean (s.d.) $)^{a}$ & $40.5(14.2)$ & $48.4(17.7)$ \\
\hline Duration of admission, days: mean (s.d.) & $52.1(44.4)$ & $52.2(49.0)$ \\
\hline Duration of detention, days: mean (s.d.) & $49.5(42.0)$ & $41.8(41.2)$ \\
\hline Diagnosis of schizophrenia or other non-affective psychosis, $n$ (\%) & $22(47.8)$ & $32(60.4)$ \\
\hline Comorbid alcohol or substance misuse, $n$ (\%) & $27(58.7)$ & $22(41.5)$ \\
\hline
\end{tabular}

a. Difference significant at $P<0.05$.

who had been discharged from a previous involuntary admission within the year; of 53 involuntary admissions in 2007, 7 (13.2\%) were such readmissions. In 2006, two admissions followed less than 1 month after the previous discharge. In 2007, two readmissions followed within 8 days of the previous admission being revoked by tribunal; one came 4 weeks after a pretribunal revocation by the consultant.

\section{Duration of involuntary admissions and duration of detentions}

There was no difference between 2006 and 2007 with respect to the mean duration of admissions including an involuntary period ( $52.1 \mathrm{v}$. 52.2. days). The mean duration of detention in 2006 (49.5 days, s.d. $=42.0$ ) was longer than in 2007 (41.8 days, s.d. $=41.2)$, but not significantly so $(t=0.91$, $P=0.36)$.

\section{Periods of voluntary status during involuntary admissions, by year}

The mean proportion of each involuntary admission spent actually detained in 2006 was 0.98 (s.d. $=0.07$ ), and in 2007 this proportion was 0.86 (s.d. $=0.21$ ). That is, under the 1945 Act, periods of voluntary status comprised a mean of $2 \%$ of the duration of involuntary admissions, whereas under the 2001 Act, this figure was $14 \%$. The difference was significant $(t=3.8, P<0.001)$.

We determined then whether the difference in duration of voluntary status during involuntary admissions was because individuals under the new Act were more likely to be admitted voluntarily and detained later in the admission, or because they were more likely to have initial involuntary status re-graded to voluntary before discharge. Involuntary patients in 2007 were no more likely to have been voluntary on admission than in $2006\left(\chi^{2}=1.3, P=0.25\right)$, but people who were initially involuntary in 2007 were more likely to become voluntary before discharge. A total of 37 involuntary admissions in 2006 were involuntary when the admission began, and of these, $3(8.1 \%)$ were re-graded to voluntary before discharge. In 2007, 47 admissions were involuntary at commencement, of which 21 (44.7\%) were re-graded. The difference in the likelihood of regrading was significant $\left(\chi^{2}=11.8, P<0.001\right)$.

\section{Discussion}

\section{Principal findings}

We hypothesised that there would be fewer involuntary admissions under the Mental Health Act 2001 than under the less rigorous Mental Treatment Act 1945, and that involuntary admissions would be shorter under the new Act than under the old Act. Neither hypothesis was supported. In fact, there were $16 \%$ more involuntary admissions to the Jonathan Swift Clinic in 2007 than in 2006. However, this difference was only seven admissions in absolute numbers and the increase was not statistically significant. As such, our findings indicate that the introduction of the Mental Health Act made no difference to the rate of involuntary admissions. We present this interpretation of our findings cautiously: another potential explanation is that there was an actual increase year on year but, because of our small catchment population and the rarity of involuntary admissions, we were underpowered to detect it. In fact, the trend appeared to continue upward after our study period ended. According to the Mental Health Commission, there were 54.8 involuntary admissions per 100000 
population in the Dublin South City catchment in $2008,{ }^{8}$ which was $16 \%$ higher than the estimated yearly value we calculated for 2007 and $26 \%$ higher than the estimated value for 2006.

We also found that the proportion of all admissions that were involuntary was higher in 2007 than in 2006. This could be interpreted as an increased propensity on the part of Jonathan Swift Clinic staff to admit involuntarily rather than voluntarily under the new Act. However, a change in this proportion (involuntary admissions/all admissions) depends as much or more on the number of voluntary admissions as on the number of involuntary admissions. As such, an increase in the proportion of all admissions that are involuntary could be a function of a reduction in voluntary admissions through better out-patient care, rather than reflecting on involuntary admissions at all. Against the latter interpretation in this case is the fact that community supports in Dublin South City did not change appreciably between 2006 and 2007. The duration of involuntary admissions was no different in 2007 than in 2006. However, periods of voluntary status during involuntary admissions were over three times longer under the 2001 Act than under the 1945 Act.

\section{Involuntary admissions under the Mental Health Act 2001}

Whether or not there was an increase in involuntary admissions in 2007, there was certainly no decrease, which we expected because of the improved protective measures that are integral to the new Act. In this respect, our results differed from those of Smith \& White in Scotland, ${ }^{5}$ and from the findings of the Mental Health Commission itself in its report on activity in $2007^{7}$ Murray and colleagues, in a recent study from the West of Ireland, also found no change in the rate of involuntary admission during the transition to the new Act. ${ }^{9}$ Other authors have found that low rates of compulsory admission require a very specific safeguard: automatic legal representation at the stage of commitment. ${ }^{10}$ In Ireland, automatic legal representation is not mandated until the first review of detention, up to 21 days after involuntary admission comes into force. The timing of legal representation in Ireland is consistent with our finding of higher rates of re-grading to voluntary status after initial detention compared with admissions prior to November 2006.

Although the improved protections in the 2001 Act may have put downward pressure on rates of detention, a number of factors may have had an opposing effect. Additional involuntary admissions under the new Act could have resulted from readmissions after revocation at tribunal. A survey of psychiatrists in Ireland found that $9 \%$ of orders revoked by tribunals were followed by immediate readmission, as these orders were deemed to have been revoked on 'technical grounds' rather than in the patients' best interests. ${ }^{11}$ Currier reported a similar finding after the introduction of the Mental Health (Compulsory Assessment and Treatment) Act of 1992 in New Zealand. ${ }^{12}$ In our study, one person was readmitted 1 day after a tribunal revoked an admission order, and one person was re-detained 8 days after revocation. Otherwise, there was little evidence of premature revocation.
Also, it is possible that consultants felt comfortable with the decision to detain an individual under the Mental Health Act because they felt that they would soon have an independent opinion to support that decision, which they did not have under the 1945 Act. Under the 1945 Act, after a reception order was completed, an individual was essentially detained for as long as the consultant, alone, decided, for up to 6 months. Arguably, under the new Act, the automatic review process paradoxically has given consultants greater freedom to detain people, knowing that the decision is less permanent and personal than previously. Against this explanation for increased rates of detention is the dislike stated by many consultants for the 'adversarial' tribunal process. ${ }^{13}$ In 2001, Obomanu \& Kennedy presciently raised concerns about the negative effects that adversarial mental health tribunals could have on patient care. ${ }^{14}$

\section{Periods of voluntary status under the Mental Health Act 2001}

We found that involuntary patients had longer periods of voluntary status as part of their admissions under the new Act than under the 1945 Act. A plausible reason for this finding is that under the Mental Health Act, automatic review of all involuntary admissions is required within 3 weeks after involuntary status commences rather than 6 months, as was required under the 1945 Act. With this timeline to consider, consultants may have become more proactive in reviewing patients' status. Responses to the survey by O'Donoghue \& Moran ${ }^{11}$ suggested that up to $20 \%$ of involuntary admissions are revoked with avoidance of mental health tribunals in mind; but widespread premature revocation would likely lead to a pattern of discharge and readmission that we did not find. Indeed, there is reason to believe that re-grading has benefits for the therapeutic alliance that extend beyond the admission. A study in Georgia found that participants who changed status from involuntary to voluntary were more likely to attend for follow-up post-discharge than those who were involuntary throughout their admissions and, surprisingly, than those who were voluntary throughout their admissions. ${ }^{15}$

\section{Limitations and external validity}

Limitations of our study include its retrospective nature, depending heavily on availability and correctness of recorded data. Relevant data on seven individuals were obtained from routine records of admission and discharge activities in the unit, as their case notes could not be traced. Additionally, the St James's service has as yet limited access to the kind of community-based treatments envisioned in recent mental health service planning documents. ${ }^{16}$ This limits the extent to which our findings can be generalised to services with more highly developed community-based activity. For instance, the neighbouring Dublin West/ Southwest mental health service has a rehabilitation team and several dedicated home-care teams, as well as generic community mental health teams. ${ }^{7}$ Arguably, rates of involuntary admission might be higher in our service than in those with a greater capacity for community management. Indeed, this may be reflected in the discrepancy 
between our findings and those of the Mental Health Commission report, although the Mental Health Commission did not provide rates of involuntary admission by service. ${ }^{7}$ The lack of a less restrictive treatment option is a key factor driving the decision to admit an individual involuntarily. ${ }^{17}$

By January 2007, psychiatrists had only limited training and experience on the practical workings of the Mental Health Act 2001, and this may have affected our findings. It might be expected that ongoing training and experience will result in improvements in the parameters we have evaluated, such as frequency of involuntary admission.

\section{Implications and future research}

The reform of the Mental Treatment Act 1945 was overdue. Its replacement, the Mental Health Act 2001, has been founded on the core principles of respect for fundamental human rights and the best interests of the individual. We found that there was a $16 \%$ increase in the rate of involuntary admission to our service after implementation of the 2001 Act, but although this increase was not significant, involuntary admissions formed a higher proportion of all admissions under the new Act than under the 1945 Act. There were longer periods of voluntary status during those admissions. This suggests an effective review process. Continuing, prospective research over the next 510 years will help determine the longer-term effects of the Act in our centre and elsewhere in Ireland.

\section{Acknowledgement}

We are grateful to Mairead Kelly (CNM), Oliver Claffey (ADON) and the medical secretaries at Jonathan Swift Clinic for their assistance in sourcing relevant hospital records for this study.

\section{About the authors}

Dr Izu Nwachukwu is a Senior Registrar, St Vincent's University Hospital, Dublin and Lecturer in Psychiatry, School of Medicine \& Medical Sciences, University College Dublin, Dr Niall Crumlish is a Consultant Psychiatrist, St James's Hospital, Elizabeth A. Heron is a Lecturer in Biostatistical Genetics, Trinity College Dublin, and Professor Michael Gill is a Consultant Psychiatrist, St. James's Hospital, Dublin, and Head, Department of Psychiatry at Trinity College Dublin, Ireland.

\section{References}

1 Brophy JJ. Forthcoming reform of Irish mental health legislation. Psychiatr Bull 1994; 18: 100-1.

2 Ganter K, Daly I, Owens J. Implementing the Mental Health Act 2001 What should be done? What can be done? Ir J Psych Med 2005; 22: 79-82.

3 Kelly BD. The Mental Treatment Act 1945 in Ireland: an historical enquiry. Hist Psychiatry 2008; 19: 47-67.

4 Kelly BD. The Irish Mental Health Act 2001. Psychiatr Bull 2007; 31 21-4.

5 Smith $\mathrm{H}$, White $\mathrm{T}$. Before and after: introduction of the Mental Health (Care and Treatment) (Scotland) Act 2003. Psychiatr Bull 2007; 31: 374-7.

6 Mental Health Commission. Annual Report 2006 including the Report of the Inspector of Mental Health Services. Mental Health Commission, 2007

7 Mental Health Commission. Annual Report 2007 including the Report of the Inspector of Mental Health Services. Mental Health Commission, 2008 .

8 Mental Health Commission. Annual Report 2008 including the Report of the Inspector of Mental Health Services. Mental Health Commission, 2009 .

9 Murray I, Hallahan B, McDonald C. Has the Mental Health Act 2001 altered the clinical profile of involuntary admissions? Ir J Psych Med 2009; 26: 179-82.

10 Dressing $\mathrm{H}$, Salize HJ. Compulsory admission of mentally ill patients in European Union member states. Soc Psychiatry Psychiatr Epidemiol 2004; 39: 797-803.

11 O'Donoghue B, Moran P. Consultant psychiatrists' experiences and attitudes following the introduction of the Mental Health Act 2001: a national survey. Ir J Psych Med 2009; 26: 23-6.

12 Currier GW. A survey of New Zealand psychiatrists' clinical experience with the Mental Health (Compulsory Assessment and Treatment) Act of 1992. N Z Med J 1997; 110: 6-9.

13 Jabbar F, Kelly BD, Casey P. National survey of psychiatrists' responses to implementation of the Mental Health Act 2001 in Ireland. Ir J Med Sci 2010; 179: 291-4.

14 Obomanu W, Kennedy HG. 'Juridogenic' harm: statutory principles for the new mental health tribunals. Psychiatr Bull 2001; 25: 331-3.

15 Craw J, Compton, MT. Characteristics associated with involuntary versus voluntary legal status at admission and discharge among psychiatric inpatients. Soc Psychiatry Psychiatr Epidemiol 2006; 41 981-8.

16 Department of Health and Children. A Vision for Change: Report of the Expert Group on Mental Health Policy. Stationery Office, 2006.

17 Lorant V, Depuydt C, Gillain B, Guillet A, Dubois B. Involuntary commitment in psychiatric care: what drives the decision? Soc Psychiatry Psychiatr Epidemiol 2007; 42: 360-5. 